\title{
The effects of parental income on the living arrangements of single adult children in Japan
}

\author{
$\underline{\text { Kei Sakata }}^{\text {a }}$ and Colin R. McKenzie ${ }^{\text {b }}$ \\ ${ }^{a}$ Faculty of Economics, Ritsumeikan University, Shiga, Japan \\ ${ }^{b}$ Faculty of Economics, Keio University, Tokyo, Japan \\ Email: ksakata@ec.ritsumei.ac.jp
}

\begin{abstract}
The purpose of this paper is to test whether the 'bribe model' as an explanation for why adult children live with their parents is valid in Japan. The bribe model argues that while parents are happy to live with their young adult child, adult children do not wish to live with their parents. As a result, parents have to 'bribe' their children with financial or non-financial transfers to induce them to live with them. Using micro data from the National Family Research of Japan (Kazoku ni tsuiteno Zenkoku Chousa) 1998 and 2003, we examine the effect of parental income on the propensity of young adult children to live with their parents, and investigate how co-residency affects the life satisfaction of parents and child. There are two main challenges in estimating the effects of parental income on the propensity of children to live with their parents. First, there is a potential endogeneity problem between the likelihood of children to live with their parents and parental income. Second, data on parental income is not available for children who live on their own. In order to deal with these two potential problems, we use the two sample instrumental variable (TSIV) method. The findings suggest that parental income has a negative not statistically significant impact on the propensity to cohabit in Japan. While children seem to be indifferent toward co-residence with their parents, co-residence has negative impacts on the marriage satisfaction and sex life satisfaction of parents. Thus, for parents privacy is a normal good in Japan, and the bribe model is not applicable to the Japanese case.
\end{abstract}

Keywords: $\quad$ Living arrangement, intra-household transfers, parental income, two sample instrumental variable (TSIV) method 


\section{INTRODUCTION}

The purpose of this paper is to re-examine the controversial question of how parental income affects the living arrangements of parents and their young adult children. In many developed countries, young adults are delaying their nest-leaving. There is a clear trend that more young adults are delaying their residential independence from their parental home, especially among Mediterranean youth (see, for example, CobbClark 2008, Giuliano 2007, and Manacorda and Moretti, 2006).

Similar trends are also observed in Japan. In 1980, the co-residency rate for young Japanese aged between 20 and 34 was $29.5 \%$, and this had increased to $46.2 \%$ by 2008 (Nishi, 2008). The co-residency rate is much higher for single adult children. According to the 2002 White Paper on the National Lifestyle, in 2001 , about $70 \%$ of single adults lived with their parents. Although a lot of attention has been devoted to the issue in the media, there are few empirical studies investigating whether the trend in Japan is due to changes in the preferences of youth or due to falls in income associated with demand shocks and the casualization of the workforce. In addition, it is unclear how parental income affects living arrangements.

Numerous studies have been undertaken in Europe and North America to examine why young people delay their nest-leaving. One stream of this research seeks an explanation for this delay by examining labour market conditions (McElroy, 1985, Card and Lemieux, 2000 and Becker et al., 2008). Some empirical evidence suggests that high housing prices and high rents have an influence on living arrangements (Haurin et al., 1993, and Ermisch, 1999). Guiso and Jappelli (2002) argue that severe imperfections in the mortgage market in Italy lead to young adults delaying their nest-leaving. Fogli (2004) provides evidence that young people choose to live with their parents when there is a high degree of employment protection and severe credit constraints. Delaying residential independence enables young adults to consume, save and invest even when they face credit constraints (Cox, 1990, Ermisch, 2003, and Fogli, 2004).

All of these studies try to unravel why young adults live with their parents and what benefits the young adults obtain from co-residing with their parents. However, it is difficult to say that the same amount of attention has been paid to why parents accept the delay in their children's nest-leaving and what they gain (or lose) in exchange for the co-residence. This paper investigates why Japanese parents live with a single young adult child and what the parents gain from the co-residence with a single young adult. Although we do not deny the importance of the factors influencing the children's behavior, in this paper, we will particularly focus on the preferences of parents and intra-household transfers.

There are some studies which highlight what parents gain/lose from co-residence with their adult children in terms of their satisfaction and financial transfers. Aquilino and Supple (1991) argue that co-residence with an unemployed or financially dependent adult child increases conflict between the parents and the child. Blanco and Kluv (2002) indicate that in Denmark, The Netherlands and Spain the nest-leaving of their child increases parental satisfaction with their housing situation. Ermisch (2003) contends that young people are more likely to live in the parental home when parental income increases, and less likely to live in the parental home when their own income increases. Manacorda and Moretti (2005) argue that in Italy, parents prefer to live with their young adult children and they 'bribe' their adult children, who prefer to live on their own, to live with them. Their empirical evidence suggests that parental income has positive effects on co-residence with a son. On the other hand, Rosenzweig and Wolpin (1993) suggest that the opposite is true in the U.S. as parental income decreases co-residence rates, and argue that American parents prefer to live on their own.

In this paper, we will focus on the bribe model of Manacorda and Moretti (2005) as it explains the preference of parents for co-residence with their children and intergenerational financial transfers simultaneously. Using data from two surveys, the National Family Research of Japan 1998 and 2003 (NFRJ1998 and NFRJ2003 hereafter), this paper estimates the effects of parental income on propensity of young adult Japanese children to live with their parents, and the effects of the co-residence on life satisfaction of both parents and child. There are two main challenges in estimating the effects of parental income on the propensity of children to live with their parents: an endogeneity problem between the likelihood of living with one's parents and parental income; and the lack of data on parental income for children who live on their own. In order to deal with these potential problems, we use the two sample instrumental variable (TSIV) method proposed by Angrist and Krueger (1992).

The relationship between the living arrangements and intergenerational financial transfers is important for Japanese tax policy as the Japanese tax system provides a deduction for dependents. The head of a household can claim a dependent deduction for each dependent who earns 1.03 million yen or less. Eligibility for the dependent deduction is not limited on the basis of the age of the dependent. A positive effect of parental income on co-residency implies financial transfers from parents to their child, and the 
dependent deduction which reduces the financial burden of dependents, may be justifiable. However, if parental income has a negative impact on co-residence, there is possibility that parents may support their children to live on their own. If parents and their child do not live together, the head of the household cannot claim the deduction for dependents. If there are income transfers from parents to their child who are living separately, some of the governmental aid to young people may need to be shifted to their parents.

Some Japanese call single young people who continue to live with their parents after completing their education "parasite singles" (Yamada, 1999). On the other hand, Genda (2006) argues that the increases in the co-residency rate are due to the collapse of the bubble economy and poor labour market conditions for the youth. If the bribe model is valid, the delay in nest-leaving of Japanese youth may be because parents discourage their children from becoming independent.

This paper's findings suggest that parental income appears to have a negative impact on the propensity to cohabit in Japan, which implies that Japanese parents prefer to live on their own, that is, privacy is a normal good for parents. Our empirical evidence also suggests that Japanese parents are more likely to be dissatisfied with their life and marriage when they live with a young adult child, but young adult children seem to be indifferent toward this co-residence. The bribe model is not applicable to the Japanese case.

The remainder of this paper consists of four sections. Section 2 outlines the methodological framework used in this paper. Section 3 describes the data. Section 4 reports and discusses the estimation results. Section 5 provides some concluding remarks.

\section{METHODOLOGY}

The purpose of this paper is twofold. First, this paper estimates the effect of parental income on coresidency. Second, this paper examines the effects of the co-residence on satisfaction of parents and their children. In this section, we discuss the identification strategy used in estimating the effects of parental income on the co-residence by the TSIV method. Then, we introduce the ordered Probit models used to estimate the effects of co-residency on the life satisfaction of parents and children.

\subsection{The Effect of Parental Income on Co-residency}

Our ultimate goal is to estimate $\beta_{1}$ in the following equation:

$$
H_{i}=\beta_{0}+\beta_{1} Y_{P i}+X_{i}^{\prime} \beta_{2}+u_{i}
$$

where $H_{i}$ is a dummy variable which takes the value unity if in family $\mathrm{i}$ an adult child lives with his/her parents, $Y_{P i}$ is parental income, $X_{i}$ is a set of control variables, and $u_{i}$ is a normally distributed error term. If parents have a taste for living with their adult children, then $\beta_{1}>0$. If parents prefer to live on their own, then the privacy of parents can be seen as being a normal good and $\beta_{1}<0$.

There are two issues that need to be treated when estimating the effects of parental income on co-residency. First, there is a potential endogeneity problem between co-residency and parental income. Second, when we estimate equation (1) using a sample of children we lack data on parental income for those children who live on their own. In order to address these two potential problems, Manacorda and Moretti (2005) apply Angrist and Krueger's (1992) two sample instrumental variable (TSIV) method.

We also use the TSIV method to solve this two layered problem. In applying TSIV, the instrument $\mathrm{Z}$ for $Y_{P i}$ and the covariates $\mathrm{X}$ must be available for both children who live with their parents and for those who live on their own. Given such an instrument $Z, \beta_{1}$ can be estimated in two steps. First, we use a parent sample to estimate a reduced form parental income equation:

$Y_{P i}=\gamma_{0}+\gamma_{1} Z_{i}+X_{i}^{\prime} \gamma_{2}+e_{i}$

Using equation (2), we can estimate the effects of $Z$ on parental income. Then, we use a children sample to estimate the following reduced form co-residence equation:

$H_{i}=\theta_{0}+\theta_{1} Z_{i}+X_{i}^{\prime} \theta_{2}+v_{i}$.

By combining (1) and (2), it can be easily shown that in (3) $\theta_{1}=\beta_{1} \gamma_{1}$, so that given consistent estimates of $\gamma_{1}$ and $\theta_{1}$, we can easily obtain a consistent estimator of $\beta_{1}$ (see Angrist and Krueger (1992)).

For parents, NFRJ1998 and NFRJ2003 contain information on variables such as age, education, employment status and marital status, and we use the years of education of the father as an instrument for the parent's income. In applying TSIV, the instrument $Z$ and the set of controls $X$ must be available for both children who live with their parents and those who live on their own as well as for their parents. As a result, 
the choice of $X$ is inevitably limited. We include the father's age and mother's age (or husband's age and wife's age for parents' sample).

Moreover, using the parents' sample, we will estimate a simple Probit model of (1) ignoring the endogeneity of parental income to check the robustness of the TSIV estimator. We estimate the effects of parental income on the propensity of parents to live with at least one adult child with the following set of control variables:e the husband's age and age squared, the wife's age and age squared, the husband's health status, the wife's health status, and the number of children.

We use the parents' sample to estimate this Probit model because it contains parental income for both parents living with their child and parents living on their own. With the children's sample, information on the parental income for those children who live on their own is not available.

One of the problems in estimating a Probit model with the parent's sample is that some parents live with more than one single adult children. Thus, we create the following dummy variable for the dependent variable.

$$
\text { Coreside }=\left\{\begin{array}{l}
1 \text { if lives with at least one single adult child } \\
0 \quad \text { otherwise }
\end{array}\right.
$$

Here, a single adult child is defined as a child who has never married, who is not attending a school/university, and who is aged between 22 and 34. In this paper, we are interested in the effects of the parental income on the co-residence with young single adults, and we want to avoid confusing such effects with those of a married child who might co-reside in order to care for his/her elderly parents.

\subsection{Effects of Co-residency on Life Satisfaction of Parents and Children}

The fundamental premises of the bribe model are that parents prefer to live with their adult child, while adult children prefer to live on their own. NFRJ contains information on many aspects of the respondent's life satisfaction rated on a scale of one to four (least satisfied to most satisfied). For parents, we use life satisfaction, marriage satisfaction, and sex life satisfaction as outcome variables for ordered Probit models. In addition to the co-residency dummy defined in section 2.1, the other control variables include: a sex dummy, age, age squared, years of education, an employment dummy ( 1 if s/he is employed), a health status dummy ( 1 if the health status is bad), the number of children, an urban dummy and region dummies. The children's sample is used to estimate the effects of their co-residency with parents on the children's life satisfaction. The main variable of interest is the co-residency dummy which for the children's sample is defined as a variable which takes the value unity if the survey respondent lives with his/her parents and 0 otherwise. As the sample is limited to single people, we do not use marriage satisfaction as an outcome variable. Given the small number of observations, we cannot use sex life satisfaction as an outcome variable in this analysis. The other covariates are a sex dummy, age, age squared, years of education, an employment dummy, a health dummy, an urban dummy and region dummies.

\section{DATA}

Our data are drawn from the 1998 and 2003 NFRJ (Kazoku ni tsuiteno Zenkoku Chousa) surveys. These surveys were conducted by the National Family Committee of the Japanese Society of Family Sociology and the Social Science and the Social Science Japan Data Archive, Information Center for Social Science Research on Japan, Institute of Social Science, the University of Tokyo. The surveys were conducted in January 1999 and 2004, respectively. In the 1998 survey, 10,500 individuals aged between 28 and 77 as of December 1998 were surveyed with a response rate of $66.52 \%$ (6,985 responses). In the 2003 survey, 10,000 individuals aged between 28 and 77 as of December 2003 were surveyed, and the response rate was $63.02 \%$ (6,302 responses). In our analysis, the two surveys are pooled together.

One of the advantages of using the NFRJ data set is that it contains rich set of information on parents and children for both children who co-reside and those who do not. We can obtain information on both parents' ages, their years of education, and their employment status. Similarly, the survey contains information for up to the third child of the respondent. The information on the children in this case includes their sex, age, years of education, and their employment status.

One major downside of the NFRJ surveys is that they do not contain information on parental income if the respondent is a young adult regardless of whether or not they live with their parents. The same is true for the children's income when the respondent is the parent. We can only obtain income information for the household, the respondent, and the respondent's spouse. 
Furthermore, NFRJ also contains information on the respondent's life satisfaction and marriage satisfaction on a scale of one to four. These variables are used as our outcome variables. In addition, the survey asks the health status of the respondent and his/her spouse using a five point scale (from 1 (very good) to 5 (very bad)). We use health status as one of the covariates in estimating life satisfaction equations and in estimating the effects of parental income on the propensity to live with at least one adult child by a Probit model. We create a dummy variable which takes the value unity if in response to the health status question the respondent answered 4 (a little bad) or 5 (very bad), and 0 otherwise.

\subsection{Parents Sample}

We estimate our models using two separate samples, a parents' sample and a children's sample. For the parents' sample, our sample is confined to respondents who satisfy the following three criteria. First, we focus on married respondents where the husband's age is $40-74$ and the wife's age 38-72. This is because the Japanese legal age for marriage is 18 for men and 16 for women. Therefore, for a father to have a 22 year old child who has just graduated from university he would need to be at least aged 40 . For a mother, she would need to be at least 38. The upper age limit is set by cutting off at around the 95 percentile. Second, we only used respondents who are currently married and who have never been divorced or widowed. Divorcees or widows may have children from their previous marriage, but the NFS surveys do not contain information on their previous marriage. We cannot identify if a child lives with their ex-spouse. Third, we exclude all observations which do not contain all the information required in estimation.

Both surveys ask respondents about who lives in their household. If the respondents are parents, the NFRJ asks respondents to indicate for their first, second and third child if the child lives with the respondent. This information is used to create the dummy variable defined in section $2-1$..

We define a single adult child as a child who has never married, who is not in a school/university, and who is aged between 22 and 34. This selection is used because we have to separate the effects of a married child who might co-reside in order to care his/her elderly parents. When constructing the dummy variable, we also excluded co-residing children who are still students. Descriptive statistics for the parents' sample are summarised in Table 1.

\section{Table 1: Descriptive Statistics}

(Parents' Sample) N=4115

\begin{tabular}{|l|r|l|}
\hline Variables & \multicolumn{1}{|l|}{ Mean } & \multicolumn{1}{l|}{ S.D. } \\
\hline Parents' income, million JPY & 7.282 & 5.786 \\
\hline Husband's education, years & 10.776 & 2.224 \\
\hline Husband's age, years & 55.210 & 9.217 \\
\hline Wife's age, years & 52.322 & 8.967 \\
\hline
\end{tabular}

\subsection{Children's Sample}

For children's sample, our sample is confined to respondents who satisfy the following criteria. First, the respondent is aged between 28 and 34. The minimum age is determined by the criteria for respondents to the NFRJ survey. The NFRJ only surveys adults who are aged 28 or over. Thus, the size of the children's sample is much smaller than the size of the parents' sample. Second, the respondent is single as explained above. Third, the respondent's parents are both alive. Moreover, the parents' must be currently married and never divorced or widowed. Finally, we exclude all observations which do not contain all the information required in estimation. Descriptive statistics for the children's sample are summarised in Table 2.

Table 2: Descriptive Statistics (Children's Sample)

\begin{tabular}{|l|c|c|c|c|c|r|}
\hline & \multicolumn{2}{|c|}{ All, N=396 } & \multicolumn{2}{c|}{ Male, N=208 } & \multicolumn{2}{c|}{ Female, N=188 } \\
\hline Variables & \multicolumn{1}{|c|}{ Mean } & \multicolumn{1}{c|}{ S.D. } & Mean & S.D & \multicolumn{1}{c|}{ Mean } & \multicolumn{1}{l|}{ S. D. } \\
\hline Living with parents & 0.773 & 0.420 & 0.760 & 0.428 & 0.787 & 0.410 \\
\hline Father's education, years & 12.722 & 2.178 & 12.654 & 2.281 & 12.798 & 2.061 \\
\hline Father's age, years & 60.636 & 4.309 & 60.875 & 4.376 & 60.372 & 4.229 \\
\hline Mother's age, years & 57.710 & 4.145 & 58.014 & 4.043 & 57.372 & 4.241 \\
\hline
\end{tabular}

\section{RESULTS}

\subsection{Estimated Results of the Effects of Parental Income on the Co-residence}

Table 3 summarises the results of estimating the effects of parental income on children's cohabitation with parents by the TSIV method. The results show that the signs of estimated coefficients on income are generally negative. However, none of the parameters is significant. To check the robustness of these results, 
we also estimated a similar Probit model using the parents' sample. In this case, the estimated coefficient is negative and statistically significant.

Table 3: The Estimated Effects of Parental Income on the Co-residence

\begin{tabular}{|l|r|r|r|r|r|r|r|}
\hline \multicolumn{7}{|c|}{ Two Sample Instrumental Variable Method } & \multicolumn{2}{c|}{ PROBIT } \\
\hline & \multicolumn{2}{|c|}{ ALL } & \multicolumn{2}{c|}{ MALE } & \multicolumn{2}{c|}{ FEMALE } & $\begin{array}{c}\text { PARENTS } \\
(\mathrm{N}=6879)\end{array}$ \\
\hline Coeff & -0.017 & -0.002 & -0.033 & -0.002 & -0.011 & 0.003 & -0.002 \\
\hline SE & 0.042 & 0.045 & 0.043 & 0.046 & 0.043 & 0.047 & $0.000 * * *$ \\
\hline Partial Elasticity & -0.126 & -0.012 & -0.239 & -0.015 & -0.079 & 0.019 & \\
\hline Region dummies & & YES & & YES & & YES & YES \\
\hline Time dummy & & YES & & YES & & YES & \\
\hline
\end{tabular}

Note: Marginal effects and their robust standard errors are shown in the Probit estimation. *** indicates significance at the $1 \%$ significant level.

\subsection{The Estimated Results of Effects of the Co-residence on Life Satisfaction}

Table 4 reports the estimates of the coefficients of the co-residency variable in ordered probit models for life satisfaction. For the parents sample, although the estimated coefficient of the co-residence dummy in the life satisfaction model is not statistically significant, co-residence with their child reduces their sex life and marriage satisfaction. In contrast, children's satisfaction seems to be indifferent to their living arrangements.

In a sense, the results here are consistent with the results in section 4.1. Unlike Italian parents (Manacorda and Moretti (2005)), Japanese parents prefer to live on their own. Thus, the bribe model is not applicable to Japan. Rather Japanese parents may assist their children to become independent when there is an increase in parental income.
Table 4: Life Satisfaction of Parents and Children

\begin{tabular}{lr}
\hline \multicolumn{1}{c}{ Parents } \\
\hline Life satisfaction $(\mathrm{N}=5329)$ & 0.014 \\
& $(0.041)$ \\
Sex life satisfaction $(\mathrm{N}=4976)$ & $-0.132 *$ \\
& $(0.072)$ \\
Marriage satisfaction $(\mathrm{N}=5360)$ & $-0.150 * *$ \\
& $(0.069)$ \\
\hline \multicolumn{2}{c}{ Children } \\
\hline Life satisfaction $(\mathrm{N}=423)$ & 0.078 \\
& $(0.124)$ \\
\hline Note: Standard errors in parentheses. ${ }^{* * *} \mathrm{p}<0.01$, \\
$* * \mathrm{p}<0.05, * \mathrm{p}<0.1$
\end{tabular}

\section{CONCLUSION}

This paper has examined whether the 'bribe model' is valid in Japan. We have estimated the effects of parental income on the propensity of young adult children to live with their parents, and investigated how co-residency affects the life satisfaction of parents and child. The findings suggest that parental income has a negative impact on the propensity to cohabit in Japan, which implies that Japanese parents prefer to live on their own. While children seem to be indifferent toward co-residence with their parents, co-residency has negative impacts on the marriage satisfaction and the sex life satisfaction of parents. Thus, privacy of parents is a normal good in Japan, and the bribe model is not applicable to the Japanese case.

\section{ACKNOWLEDGEMENT}

The first author wishes to acknowledge the financial assistance provided by the Japan Society for the Promotion of Science Grant in Aid for Scientific Research No. 22730239 for a project on the "The Analysis of Single Children living with Their Parents". The second author wishes to acknowledge the financial assistance provided by a Global Center of Excellence (GCOE) Award made to the Graduate School of Economics and the Graduate School of Business and Commerce at Keio University for Raising Market Quality- Integrated Design of Market Infrastructure. Both authors also wish to acknowledge the kind permission of the National Family Committee of the Japanese Society of Family Sociology and the Social Science and the Social Science Japan Data Archive, Information Center for Social Science Research on Japan, Institute of Social Science, University of Tokyo in making available the data in the "National Survey on Families (NSF)" (Kazoku ni tsuite no Zenkoku Chousa) for use in the analysis in this paper. 
Sakata and McKenzie, The effects of parental income on the living arrangements of single adult children...

\section{REFERENCES}

Angrist, J.D., and Krueger, A.B. (1992). The effect of age at school entry on educational attainment: An application of instrumental variables with moments from two samples. Journal of the American Statistical Association, 87, 328-336.

Aquilino, W.S., and Supple, K. R. (1991). Parent-child relations and parents' satisfaction with living arrangements when adult children live at home. Journal of Marriage and Family, 53, 13-27.

Cabinet Office (Japan) (2003). Annual Report on the National Lifestyle for FY 2003: Deflation and Lifestyle- Young Jobhoppers Now (Heisei 15 Nenban Kokumin Seikatsu Hakusho: Defure to Seikatsu Jakunen Furita no Genzai (Ima)), Tokyo. (http://www5.cao.go.jp/seikatsu/whitepaper/h15/honbun /index.html, accessed 22 June 2011).

Card, D., and Lemieux, T. (2000). Adapting to circumstances: The evolution of work, school, and living arrangements among North American youth, in Blanchflower, D.G., and R.B. Freeman (eds), Youth Employment and Joblessness in Advanced Countries, University of Chicago Press, Chicago, 171-213.

Cobb-Clark, D.A. (2008). Leaving home: What economics has to say about the living arrangements of young Australians. Australian Economic Review, 41(2), 160-176,

Cox, D. (1990). Intergenerational transfers and liquidity constraints. Quarterly Journal of Economics, 105, $187-217$.

Ermisch, J. (1999). Prices, parents, and young people's household formation. Journal of Urban Economics, $45,47-71$.

Ermisch, J. (2003). An Economic Analysis of the Family, Princeton University Press, Princeton, NJ.

Fogli, A. (2004). Endogenous labor market rigidities and family ties. unpublished working paper, New York University and the Federal Reserve Bank of Minneapolis, September.

Genda, Y (2006). A Nagging Sense of Job Insecurity: The New Reality Facing Japanese Youth $2^{\text {nd }}$ ed, IHouse Press, Tokyo.

Giuliano, P. (2007). On the determinants of living arrangements in Western Europe: Does cultural origin matter?. Journal of the European Economic Association, 5(5), 927-52.

Guiso, L., and Jappelli, T. (2002). Private transfers, borrowing constraints, and the timing of homeownership. Journal of Money, Credit, and Banking, 34, 315-339.

Haurin, D.R., Hendershott, P.H., and Kim, D. (1993). The impact of real rents and wages on household formation. Review of Economics and Statistics, 75, 284-293.

Heckman, J.J., Ichimura, H. and Todd, P. (1997). Matching as an econometric evaluation estimator: Evidence from evaluation a job training programme. Review of Economic Studies, 64(4), 605-654.

Jappelli, T., Pischke, J.-S. and Souleles, N.S. (1998). Testing for liquidity constraints in Euler equations with complementary data sources. Review of Economics and Statistics, 80(2), 251-262.

Manacorda, M. and Moretti, E. (2006). Why do most Italian young men live with their parents? Intergenerational transfers and household structure. Journal of the European Economic Association, June 2006, 4(4), 800-829.

Martonez-Granado, M. and Ruiz-Castillo, J. (2002). The decisions of Spanish youth: A cross-section study. Journal of Population Economics, 15, 305-330.

McElroy, M.B. (1985). The joint determination of household membership and market work: The case of young men. Journal of Labor Economics, 3(3), 293 - 316.

Nishi, F. (2008). Recent developments of young singles living with their parents No. 7 (Oya to dokyou no jakunen mikonsha no saikin no jokyo sono 7). Tokei, Japan Statistical Association, June, 1-5.

Rosenzweig, M.R. and Wolpin, K.I. (1993). Intergenerational support and the life-cycle of young men and their parents - Human capital investment, coresidence and intergenerational financial transfers. Journal of Labor Economics, 11(1) Part 1(Essays in Honor of Jacob Mincer), 84-112.

Wakabayashi, M. and Horioka, C.Y. (2009). Is the eldest son different? The residential choice of siblings in Japan. Japan and the World Economy, 21(4), 337-348.

Yamada, M. (1999). The Age of Parasite Singles (Parasaito Shinguru no Jidai), Chikuma Shobo, Tokyo. 